\title{
Computing knowledge and Skills Demand: A Content Analysis of Job Adverts in Botswana
}

\author{
Y. Ayalew, Z. A. Mbero, T. Z. Nkgau, P. Motlogelwa, A. Masizana-Katongo \\ Department of Computer Science, University of Botswana \\ \{ayalew, mberoz, nkgautz, motlogel, masizana\}@ mopipi.ub.bw
}

\begin{abstract}
This paper presents the results of a content analysis of computing job adverts to assess the types of skills required by employers in Botswana. Through the study of job adverts for computing professionals for one year (i.e., January 2008 to December 2008), we identified the types of skills required by employers for early career positions. The job adverts were collected from 7 major newspapers (published both daily and weekly) that are circulated throughout the country. The findings of the survey have been used for the revision and development of curricula for undergraduate degree programmes at the Department of Computer Science, University of Botswana.

The content analysis focused on the identification of the most sought after types of qualifications (i.e., degree types), job titles, skills, and industry certifications. Our analysis reveals that the majority of the adverts did not set a preference to a particular type of computing degree. Furthermore, our findings indicate that those job titles and computing skills which are on high demand are not consistent with previous studies carried out in the developed countries. This requires further investigation to identify reasons for these differences from the perspective of the practices in the IT industry. It also requires further investigation regarding the degree of mismatch between the employers computing skills demands and the knowledge and skills provided by academic programmes in the country.
\end{abstract}

Keywords - computing job adverts; job adverts in Botswana; content analysis

\section{INTRODUCTION}

Computing professionals have enjoyed better employment packages and job opportunities due to high demand for their knowledge and skills worldwide [1, 2]. As most organizations and businesses are becoming highly dependent on Information Technology, the demand for such professionals is expected to increase. To satisfy this demand, the knowledge and skills possessed by graduates with computing degrees should match with the types and variety of skills needed by employers. One recent trend observed is that employers are continually demanding a mix of skills in addition to technical skills from computing graduates [1, 3]. Academic institutions need to scrutinize this trend so that they can align their programmes and curricula with industry needs. In Botswana, employers' needs and expectations from computing graduates have not been properly studied. As the skills demand of employers may change from time to time, studies should be carried out regularly so that the patterns of growth for the future can be identified.
This research was motivated by the need to better understand the current and future employers' needs for computing graduates in Botswana. As the only public University in the country, a lot is expected from this institution to produce workforce that can meet the demands of employers. Realizing this expectation, the Department of Computer Science planned to diversify its programmes both at the undergraduate and graduate levels. To do so, the department needs to understand the competencies that are needed and will be needed by the job market. Currently, the department offers undergraduate degree programmes in Computer Science and in Information Systems.

In the past curricula revision used to be carried out in the department based on the perceptions of academicians of what might be needed by the employers. However, this trend is no longer practical because there is a gap in the perceptions of employers and academicians about the knowledge, skills and competencies required of computing graduates $[4,5]$. Different studies have also identified that employers are demanding a variety of new skills which were not found in the mainstream computing studies.

In the context of Botswana, there is also a perception that, recently, graduates with computing degrees are having difficulties in getting employment. This is in contrary to the global trend where the demand for computing professionals is still high. For example, according to the Unites States Bureau of Labour and Statistics[6], occupations in the area of network systems and communications, application development and systems software development will be on the rise in the years to 2012. The situation in Botswana calls for further investigation to get an understanding of where the problem lies. It could be that graduates are not well prepared in terms of the required knowledge and skills for employment or that the industry is not well developed to avail employment opportunities for entry-level graduates. In our search for past studies focusing on Botswana, we were unable to find a study describing the knowledge and skills in demand by employers for computing graduates. Therefore, this study aims to investigate the knowledge and skills required for computing graduates. Specifically, this study focuses on the identification of knowledge and skills demanded for early career/entry-level positions.

The objectives of the study are as follows:

1. Identify the types of degree qualifications that are in demand 
2. Identify the types of knowledge and skills required for entry-level positions

3. Assess to what extent industry certifications are required for entry-level positions

In order to achieve our objectives, we collected job adverts from the 7 major newspapers (published both daily and weekly) in the country for the period January 2008 to December 2008. Job adverts are widely used as a means of expressing employers' needs regarding skills and competencies of prospective employees. A number of studies [3-5, 7-11] have used job adverts as a source of data for analysing skills in demand in different disciplines. Therefore, we assume that employers are able to express correctly the types of skills they want from their prospective employees when they advertise in newspapers.

Examples of job adverts included were those that require a bachelor degree in Computer Science, Information Systems, Information Technology or related discipline with less than or equal to two years of experience requirements. We consider that such job adverts describe early career positions. Kennan et al. [5] defined that "early career or entry level positions are those positions requiring new graduates and those with up to three years work experience". In the context of Botswana, most employers advertise jobs in newspapers and hence the adverts collected from the major newspapers should be a sufficient source to make any conclusions. Online job adverts are not common in the country as Internet is not yet the preferred medium for advertisement of jobs.

The rest of the paper is organized as follows: Section 2 describes the research method used in this research. The analysis and findings of the survey are presented in Sections 3 and 4 respectively. Sections 4 includes also a discussion of the main issues resulted in from the data analysis. Finally, Section 5 presents the main points of the survey result.

\section{RESEARCH METHOD}

One major activity during curriculum design is the identification of knowledge and skills that are in demand and those job categories and skills that are anticipated to grow in the future. This identification can be achieved using surveys, interviews, content analysis of job adverts, etc. or any combinations of these techniques [3].

The content analysis method was chosen for the job advert analysis from major newspapers in the country. According to Krippendorff [12], content analysis is a "research technique for making replicable and valid inferences from texts (or other meaningful matter) to the contexts of their use". As a scientific tool, content analysis provides new insights and increases a researcher's understanding of particular phenomena, or informs practical actions. Content analysis has been applied in different fields [13, 14]. Different studies used content analysis for analysing job adverts $[8,11]$ and indicated that content analysis helped to identify skills in demand at present and identify shifts in the patterns of skill demands over time.
A content analysis of job adverts for software developers by Surakka [9] discovered that the requirement for technical skills more than doubled in the years 1990 to 2004. Gallivan et. al [4] conducted a content analysis study of job adverts in printed media from 1988 to 2003 and discovered that employers were increasingly requiring a variety of skills from new IT employees. Their study also revealed that there was a recruitment gap in that even though employers wanted allrounded employees, their adverts demanded more IT technical skills. Other similar studies using content analysis were conducted to identify skills demand of employers in different countries $[4,5,8,10,14]$.

For our study, job adverts were collected from 7 major newspapers (Mmegi, Daily News, Gazette, Guardian, Midweek Sun, Sundays Standard, and Voice) for the period January 2008 to December 2008. Two of the newspapers are published daily while the other five are published weekly. These newspapers are circulated country-wide. As online job adverts are not popular yet in the country, we believe that the job adverts in these Newspapers have a fair representation of job adverts in the country.

In order to carry out the data collection, 6 research assistants (i.e., demonstrators and teaching assistants in the department with at least a bachelor degree in Computer Science or Information Systems) were employed. The research assistants were given a template that contains information items that need to be recorded by scanning the newspapers they were assigned (sample template is attached as an appendix). The Newspapers were available at the University Library to the research assistants for the indicated period. Since we are planning to use the result of this survey for curricula revision of the existing undergraduate programmes (Computer Science and Information Systems) and introduce new undergraduate programmes in other Computing disciplines, the research assistants were asked to record any job advert requiring a degree in one or more of the computing disciplines (as defined in [15]).

\section{ANALYSIS}

In our analysis, we excluded some of the adverts for various reasons. The first group of adverts excluded were those requiring a qualification different from Bachelors degree. Since our main focus is to get an understanding of the skills requirement for early career employees in Computing (B.Sc. degree), we removed those requiring other than B.Sc. degree. We also excluded qualifications such as Degree/Diploma or $\mathrm{MSc} / \mathrm{BSc}$ for an advert as these types of mixed-qualification adverts are not specifically targeting B.Sc. degree graduates. Finally, we excluded those adverts which were redundant; meaning those adverts appearing in multiple newspapers. This is common since the same advert can be listed in different newspapers. In addition, the same advert can appear in different issues of the same newspaper.

The criterion we used to remove redundant adverts is using vacancy number. Unfortunately, not all adverts have vacancy number. Therefore, to minimize the redundancy, we scanned 
those adverts manually. Using all these elimination criteria, we reduced the number of job adverts from 494 (initially collected) to 131 . The following table shows the number of adverts for each Newspaper.

TABLE I. ADVERTS PER NEWSPAPER

\begin{tabular}{|l|l|l|l|l|l|l|l|l|}
\hline Newspaper & Adverts & Positions & Diploma & $\begin{array}{l}\text { BSc(<= } \\
\text { 2years) }\end{array}$ & $\begin{array}{l}\text { BSc(> } \\
\text { 2years) }\end{array}$ & MSc & PhD & Other* \\
\hline Daily News & 78 & 341 & 15 & 37 & 14 & 4 & 0 & 8 \\
\hline $\begin{array}{l}\text { Sunday } \\
\text { Standard }\end{array}$ & 62 & 76 & 9 & 6 & 44 & 3 & 0 & 0 \\
\hline Gazette & 58 & 81 & 6 & 15 & 30 & 7 & 0 & 0 \\
\hline Voice & 18 & 249 & 3 & 6 & 8 & 1 & 0 & 0 \\
\hline Midweek Sun & 36 & 44 & 0 & 12 & 22 & 0 & 0 & 2 \\
\hline Guardian & 55 & 73 & 8 & 8 & 33 & 4 & 0 & 2 \\
\hline Mmegi & 187 & 215 & 28 & 47 & 90 & 11 & 5 & 6 \\
\hline Total & $\mathbf{4 9 4}$ & $\mathbf{1 0 7 9}$ & $\mathbf{6 9}$ & $\mathbf{1 3 1}$ & $\mathbf{2 4 1}$ & $\mathbf{3 0}$ & $\mathbf{5}$ & $\mathbf{1 8}$ \\
\hline
\end{tabular}

* refers to those that do not fall into one of the specified categories.

\section{A. Job Categories}

Since the department is, currently, running B.Sc. degree programmes in Computer Science and Information Systems and has a plan to launch new programmes in other computing disciplines, we opted to use generic computing job categories that can describe the knowledge and skills required of computing graduates. Gullivan et al. [3] developed computing skill categories for IT professionals in their study of changing demand patterns for IT professionals. In order to come up with those job categories, they used Computerworld job/skill classifications scheme, literature and evolved it through Delphi refinement approach using Faculty members in their institution. The job categories they introduced helped them to assess the level of demand of each job category. They identified the increase in demand for software engineers.

Litecky et al. [8] also developed job categories using web content mining techniques to identify job categories and the associated skills needs prevalent in the computing profession in the USA. They extracted job adverts of about 20 months from three online sources for jobs requiring a degree in Computer Science, Information Systems, and other computing programs. They analyzed the data collected using cluster analysis to come up with clusters of job categories and identified 19 job titles and 24 most frequently mentioned skills in computing job adverts. The job definitions and the associated skills required for these titles are provided in [8]. These job definitions were finally categorized into five larger job classifications to minimize the similarities among the job definitions. The classifications include Web developers, software developers, database developers, managers, and analysts. Nunamaker et al. [16] also provided job classification scheme used in the 1980s which provided the categories: programmers (software developers), technical specialists, business systems analysts, end-user support, and computer operators \& data-entry clerks.
Another study by Liu et al. [10] provided five broad skill categories: Programming languages, Web development, Database, Networking, and Operating systems \& Environments. Each category is further divided into different types of skills. For example, under programming languages category, skills such as C++, Java, VB, etc were listed. They reported the level of demand of each skill in each of the five categories. For example, in the programming languages category, $\mathrm{C}++$ /Visual $\mathrm{C}++$ skill is in high demand with $38.64 \%$.

From the above classification schemes, we can see that some are based on job titles $[3,8,16]$ and others are based on skill categories [5, 10]. However, both approaches list the associated skills to the job titles or skill categories. In addition, we observed that some focus only on technical skills while others include other non-technical skills such as project management, business strategy, etc. As many recent studies [5, 8] indicated, the trend is that most employers demand a mix of technical and non-technical skills from computing graduates. Another difference among the different schemes is the level of detail in skills categorizations. For example, the job category developed by Litecky et al. [8] indicated how specialized the skill requirements are in the USA. Such categorization may not be appropriate in developing countries where the industry is not well developed. On the other hand, classification schemes like the one provided by Nunamaker et al. [16] indicate very generic classifications which were appropriate in the past but may not be applicable at present.

In Botswana, we were unable to find standardized job titles and their associated skills that can be used by most employers. In our preliminary analysis, we observed that different job titles are used for the same positions. For this study, using the various literature resources $[8,17,18]$ and our own experience, we adopted a classification scheme as given below in Table 2 . 
TABLE II. JOB TITLES AND ASSOCIATED SKILLS

\begin{tabular}{|c|c|c|}
\hline Job title & $\begin{array}{l}\text { Job description } \\
\end{array}$ & Major skills required \\
\hline Systems analyst & $\begin{array}{l}\text { researches problems, plans solutions, } \\
\text { recommends software and systems, } \\
\text { and coordinates development to meet } \\
\text { business or other requirements }\end{array}$ & $\begin{array}{l}\text { Programming, operating systems, } \\
\text { hardware platforms }\end{array}$ \\
\hline Education & $\begin{array}{l}\text { covers a range of areas, including } \\
\text { tertiary and secondary teaching; } \\
\text { vendor training; corporate trainers } \\
\text { and trainers / managers of specialist } \\
\text { training organizations. }\end{array}$ & Not specific \\
\hline User/technical support & $\begin{array}{l}\text { Provide support regarding application } \\
\text { packages, computer systems, } \\
\text { networks to end users }\end{array}$ & $\begin{array}{l}\text { Network, packages, operating } \\
\text { systems, installation, upgrading }\end{array}$ \\
\hline $\begin{array}{l}\text { Systems administrator } \\
\text { (systems manager) }\end{array}$ & $\begin{array}{l}\text { Administration of end-user systems } \\
\text { and workstations as well as } \\
\text { networking and telecommunications }\end{array}$ & $\begin{array}{l}\text { Operating systems (Windows, } \\
\text { Linux, Unix), security, } \\
\text { certification, networking }\end{array}$ \\
\hline Network administrator & $\begin{array}{l}\text { Responsible for the maintenance of } \\
\text { computer hardware and software that } \\
\text { comprises a computer network. } \\
\text { Includes the deployment, } \\
\text { configuration, maintenance and } \\
\text { monitoring of networks equipment. It } \\
\text { can also be called Network specialist, } \\
\text { network designer, network support, or } \\
\text { LAN administrator }\end{array}$ & $\begin{array}{l}\text { Operating systems, security, } \\
\text { protocols (TCP/IP), Cisco }\end{array}$ \\
\hline Database administrator & $\begin{array}{l}\text { Works with the administrative } \\
\text { component of databases. The role } \\
\text { includes developing and designing } \\
\text { the database strategy, monitoring and } \\
\text { improving database performance and } \\
\text { capacity, and planning for future } \\
\text { expansion requirements. }\end{array}$ & $\begin{array}{l}\text { DBMS (Oracle/MS SQL } \\
\text { Server/mySQL, etc.), SQL, } \\
\text { Security, certifications }\end{array}$ \\
\hline IT manager & $\begin{array}{l}\text { plan, administer and review the } \\
\text { acquisition, development, } \\
\text { maintenance and use of computer and } \\
\text { telecommunication systems within an } \\
\text { organization }\end{array}$ & $\begin{array}{l}\text { Sound technical experience, } \\
\text { leadership, strategy, finance, } \\
\text { accounting, knowledge of } \\
\text { administrative procedures such as } \\
\text { budgeting, quality assurance and } \\
\text { human resources }\end{array}$ \\
\hline Web developer & $\begin{array}{l}\text { Web application development using a } \\
\text { variety of programming languages } \\
\text { and tools }\end{array}$ & $\begin{array}{l}\text { HTML, XML, JavaScript, AJAX, } \\
\text { Java, ASP, SQL, PHP }\end{array}$ \\
\hline Software developer & $\begin{array}{l}\text { Involved in the specification, } \\
\text { designing, and implementation of a } \\
\text { software system and work with } \\
\text { different languages and associated } \\
\text { tools }\end{array}$ & $\begin{array}{l}\mathrm{C} / \mathrm{C}++, \mathrm{C} \#, \text {.NET, Java, OOP, } \\
\text { software development }\end{array}$ \\
\hline Database developer & $\begin{array}{l}\text { Working with SQL, and different } \\
\text { DBMS, programming, and systems } \\
\text { analysis }\end{array}$ & SQL, DBMSs, programming \\
\hline Project management & involves the selection, approval and & Estimation, scheduling, \\
\hline
\end{tabular}




\begin{tabular}{|l|l|l|}
\hline & $\begin{array}{l}\text { initiation, planning, implementation } \\
\text { and tracking, reporting and review of } \\
\text { a project in the context of IT projects }\end{array}$ & $\begin{array}{l}\text { controlling, resources } \\
\text { management }\end{array}$ \\
\hline $\begin{array}{l}\text { Other (consultant, graphic } \\
\text { designer, etc) }\end{array}$ & Different non-common job titles & \\
\hline
\end{tabular}

\section{FINDINGS \& DISCUSSION}

An analysis of our findings regarding the demand for the computing degrees, job titles, specific computing skills and industry certifications is provided below.

\section{A. Education requirements}

Under education requirement, we assessed the level of demand for the different B.Sc. degree (computing) qualifications in the country. Since we are interested in to assess the types of B.Sc. degree qualifications that are in demand for entry level positions and their associated skills, we focus on those adverts requiring less than or equal to 2 $(<=2)$ years of experience. The findings regarding the demand for the different degree qualifications are presented numerically in Table 3 and graphically in Figure 1.

TABLE III. DEMAND FOR COMPUTING DEGREES

\begin{tabular}{|c|c|c|c|c|c|c|c|}
\hline Newspaper & $\begin{array}{l}\text { Computer } \\
\text { Science }\end{array}$ & $\begin{array}{l}\text { Information } \\
\text { Systems }\end{array}$ & $\begin{array}{l}\text { Software } \\
\text { Engineering }\end{array}$ & $\begin{array}{l}\text { Computer } \\
\text { Engineering }\end{array}$ & $\begin{array}{l}\text { Computing } \\
\text { (Any) }\end{array}$ & Total & Percent \\
\hline Daily News & 27 & 0 & 0 & 0 & 10 & 37 & $28.2 \%$ \\
\hline Mmegi & 28 & 3 & 0 & 1 & 15 & 47 & $35.9 \%$ \\
\hline $\begin{array}{l}\text { Sunday } \\
\text { Standard }\end{array}$ & 3 & 0 & 0 & 0 & 3 & 6 & $4.6 \%$ \\
\hline Gazette & 2 & 0 & 0 & 0 & 13 & 15 & $11.5 \%$ \\
\hline Voice & 1 & 1 & 0 & 0 & 4 & 6 & $4.6 \%$ \\
\hline $\begin{array}{l}\text { Midweek } \\
\text { Sun }\end{array}$ & 3 & 0 & 0 & 0 & 9 & 12 & $9.2 \%$ \\
\hline Guardian & 1 & 1 & 0 & 0 & 6 & 8 & $6.1 \%$ \\
\hline Total & 65 & 5 & 0 & 1 & 60 & 131 & \\
\hline Percent & $49.6 \%$ & $3.8 \%$ & $0.0 \%$ & $0.8 \%$ & $45.8 \%$ & & \\
\hline
\end{tabular}

In terms of the qualification type classification, we could have added Information Technology as this qualification is now a well established qualification according to the recent ACM/IEEE curricula guidelines. However, its use in the industry is still confused between its meaning as a Computing discipline and its generic meaning (i.e., referring to the IT industry). Therefore, we were not sure which meaning the advert is referring to when the education requirement is specified as "Degree in IT". Hence we classified such adverts under "Computing (any)". In addition, under education requirement, some adverts specify a list of alternative fields such as "Degree in Computer Science/ Information Systems" etc. We classified such requirements as "Computing (any)" since they did not indicate preference to a particular Computing field of study.
The result in Table 3 (or Figure 1) above shows that Computer Science degree is still in high demand $(49.6 \%)$ for early career positions while Information Systems has a low demand (3.8\%). We can also see that the demand for computing (any) degree is also high (45.8\%). This could be an indicator that either employers do not care about the specific computing degree type as long as prospective employees are equipped with the desired skills or the tasks for which employers plan to recruit are so generic that anyone with a computing degree should be able to accomplish. Another interesting result is that there is no demand for software engineering degree in contrary to worldwide trend where the demand for software engineers is growing especially in developed countries. This could also be an indicator that there 
is no much software development locally or a degree in software engineering is still not known to employers.

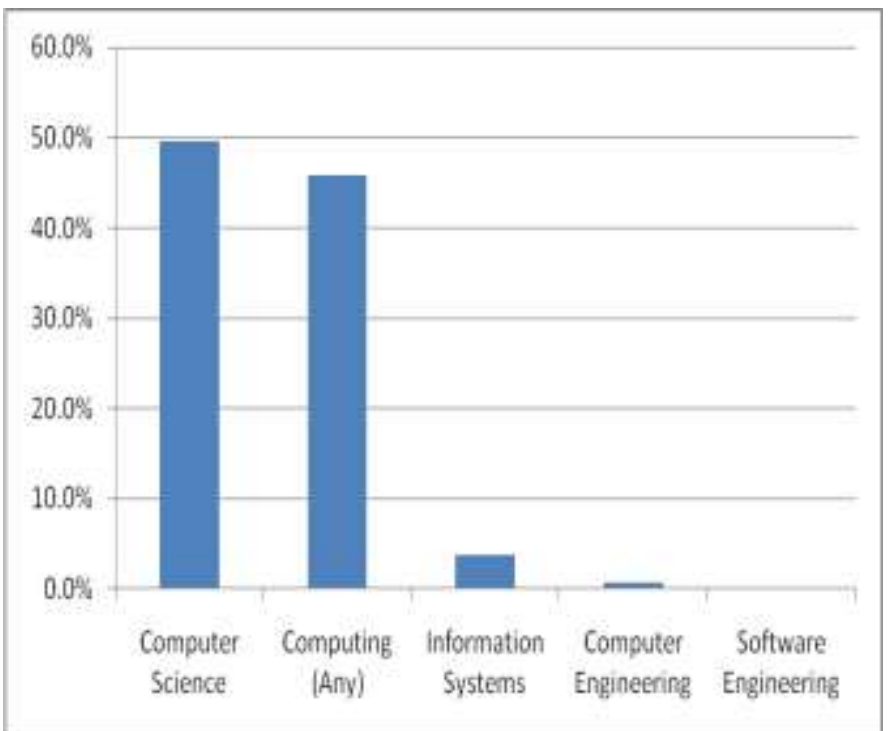

Figure 1. Demand for computing degrees

It is interesting to see that Computer Science degree has still a high demand compared to the other computing degrees. This information is particularly important for prospective students so that they can make their decisions regarding the choice of field of study based on job prospects. However, it is doubtful whether the demand for Computer Science degree represents the actual demand for Computer Science graduates. In our observation, the job descriptions of those adverts that required Computer Science degree are not typical descriptions requiring a computer science degree. Most of those job descriptions looked appropriate for anyone who has a computing degree. It could be that employers are more familiar with the computer science degree than the other computing degrees because it has been offered by the University since 1992 while Information Systems degree started to be offered in 2002.

\section{B. Job titles}

Even though the classification of the job titles is based on the description given in Table 2 (Section 4.1), we realized that it was difficult to come up with the same classification by different people as some of the job titles appear to fit into different job titles in the classification provided. For example, by looking at the job description of a particular advert, some one might classify it as a software developer position while others might classify it as database developer position when the description equally emphasizes on the database and software development skills. To minimize such misclassifications, the authors independently classified the job adverts and then discussed together to reach a consensus as to the best classification

The findings regarding the demand for the different job titles are presented numerically in Table 4 and graphically in Figure 4

\section{TABLE IV. DEMAND FOR JOB TITLES}

\begin{tabular}{|c|c|c|c|c|c|c|c|}
\hline Job Title & ख़ & 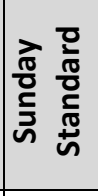 & 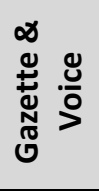 & 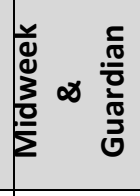 & & 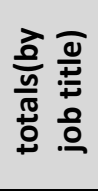 & 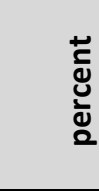 \\
\hline Systems Analyst & 8 & 1 & 6 & 2 & 5 & 22 & 16.8 \\
\hline Education & 9 & 0 & 0 & 2 & 9 & 20 & 15.27 \\
\hline software developer & 2 & 2 & 3 & 3 & 6 & 16 & 12.22 \\
\hline $\begin{array}{c}\text { other(consultant, graphic } \\
\text { designer) }\end{array}$ & 7 & 0 & 0 & 1 & 5 & 13 & 9.93 \\
\hline network administrator & 1 & 1 & 0 & 3 & 7 & 12 & 9.17 \\
\hline database administrator & 2 & 1 & 3 & 4 & 2 & 12 & 9.17 \\
\hline User/technical support & 2 & 1 & 5 & 1 & 2 & 11 & 8.4 \\
\hline systems administrator & 3 & 0 & 1 & 1 & 3 & 8 & 6.11 \\
\hline IT manager & 0 & 0 & 1 & 1 & 6 & 8 & 6.11 \\
\hline database developer & 3 & 0 & 2 & 2 & 0 & 7 & 5.35 \\
\hline web developer & 0 & 0 & 0 & 0 & 1 & 1 & 0.77 \\
\hline project management & 0 & 0 & 0 & 0 & 1 & 1 & 0.77 \\
\hline
\end{tabular}




\section{totals (\# of adverts by: )}

\section{Job Titles}

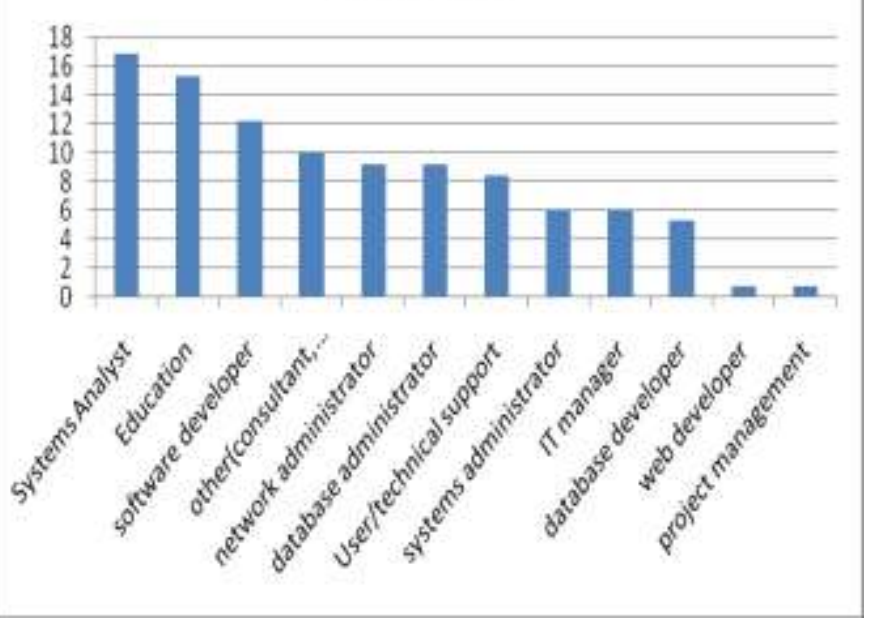

Figure 2. Demand for computing degrees

The highest job title in demand is Systems Analyst (16.8\%) followed by Education (15.27\%) and Software Developer $(12.22 \%)$. The two findings that are in contrary to world wide trends are the demand for Education (15.27\%) and Web developer $(0.77 \%)$.

It is interesting to observe that the job title with the highest demand is systems analyst which is not a typical job title for computer science graduates. This title is usually more suitable for Information Systems graduates. Therefore, it is likely that the problem lies in that employers are not able to properly differentiate the different computing disciplines when they specify educational requirements in their adverts. It is important to note that the high ranking of systems analyst job title is similar to findings in other studies [5, 19].

The demand for education is the second highest (15.27\%) compared to the other job titles. This is probably a finding which is in contrary to other studies carried elsewhere. It could be an indicator of the job situation in a developing country context. The following two reasons might explain the situation: 1) that many private higher learning institutions are being established in the country and these institutions usually employee new graduates to fill their positions as those graduates with M.Sc. and $\mathrm{PhD}$ are scarce; 2) a new subject called "Computer Studies" is offered in most government secondary schools and new graduates are usually employed to teach this subject.

With the growing importance of the web, the demand for experts in this area is continuously increasing. It is expected that Web technology will provide the foundation for most future software systems. For this reason some Universities actually started to design web-centric curriculum to satisfy the ever increasing demand [20]. However, our finding shows the

\begin{tabular}{l|l|l|l|l}
21 & 20 & 47 & 131 & 100 \\
\hline
\end{tabular}

contrary where the demand for web developers is the least $(0.77 \%)$. This could be an indicator that there is no much web development activity locally.

\section{Skills}

In order to analyze the various skills that are in demand, we adapted the skills categories provided in [10] as this scheme lists the most likely skill categories for entry-level Computing positions. This scheme basically aggregates the skills listed in Table 2 corresponding to the different job titles. The skill categories are Programming (with skill set of $\mathrm{C} / \mathrm{C}++, \mathrm{C} \#$, Java, .NET, VB, generic, others), Web Development (with skill set of Java/Java script, XML, PHP, ASP, HTML, generic, others), Database (with skill set of Oracle, MS SQL Server, MySQL, MS Access, generic, others), Operating Systems (Windows, Linux, UNIX, generic, others), and Networking (with skill set of network design, network management, network security, generic, others). In each of the skill categories, "generic" refers to generic skills without any preference to specific skills. For example, in the programming category, generic refers to generic programming skills without preference to a specific programming language. Similarly, in all the skill categories, "others" refers to specific skills specified different from the ones provided in each of the skill categories. For example, in the programming category, if one specifies skill in Perl, it is considered as "Others" as it is different from the specific skills listed in the programming category.

In the programming skill category, generic programming skill accounts for $83.3 \%$ of the programming skills specified followed by $\mathrm{C} / \mathrm{C}++(11.1 \%)$ and .NET (5.6\%). In the web development category, generic web development skill constitutes $66.7 \%$ followed by HTML (13.3\%) and Java/Java script $(6.7 \%)$. In the database category, generic database skill constitutes $77.3 \%$ followed by Oracle (18.2\%) and MS SQL Server $(4.5 \%)$. In the operating systems category, generic operating systems skill constitutes $57.7 \%$ followed by Microsoft Windows (23.1\%) and UNIX (19.2\%). Finally, in the networking category, generic networking skill constitutes $77.4 \%$ followed by network management (19.4\%) and security $(3.2 \%)$.

In terms of the skill categories, more adverts specified skills in networking $(27.7 \%)$ than the other categories. The other skill categories' demand is as follows: operating systems $(23.2 \%)$, database $(19.6 \%)$, programming $(16.1 \%)$ and web development $(13.4 \%)$.

A clear trend that can be observed from the adverts is that the majority of them specify generic skills as opposed to specific skills. Even though it is difficult to make conclusions why most of them prefer generic skills, this pattern might be an indicator that most jobs do not require specialized skills. This in turn could be an indicator that the industry is not yet mature enough to engage the services of specialised professionals. This finding might also indicate a correlation with types of computing degrees specified in adverts. We saw that many of the adverts did not set a preference to a particular type of 
computing degree in their adverts. For example, many of the adverts specify, under education requirement, a list of alternatives such as degree in computer Science/Information Systems $/ . .$. or related. This finding is also in contrary to other studies conducted especially in the developed countries where employers specify specific skills that are more relevant for their tasks. The actual reason needs further investigation. It could be that most job positions require generic skills or employers failed to include the specific skills desired in their adverts.

\section{Industry certifications}

Even though entry-level positions are expected to focus on the academic performance of graduates at their University education and their potential to succeed at work, we observed that some adverts actually require additional industry certifications in addition to academic degrees. Table 5 below presents the types of certifications that are required for entry level positions in the Botswana Computing job market.

TABLE V. DEMAND For INDUSTRY CerTIFICATIONS

\begin{tabular}{|l|c|c|}
\hline Certification & Frequency & Percentage \\
\hline MCSE & 8 & $21.62 \%$ \\
\hline$A+$ & 5 & $13.51 \%$ \\
\hline K2 SAP & 4 & $10.81 \%$ \\
\hline OCP & 3 & $8.11 \%$ \\
\hline OCA & 3 & $8.11 \%$ \\
\hline ICDL & 2 & $5.41 \%$ \\
\hline MCP & 2 & $5.41 \%$ \\
\hline CCNA & 2 & $5.41 \%$ \\
\hline CCVP & 1 & $2.70 \%$ \\
\hline N+ & 1 & $2.70 \%$ \\
\hline CISA & 1 & $2.70 \%$ \\
\hline ITIL & 1 & $2.70 \%$ \\
\hline ISEB & 1 & $2.70 \%$ \\
\hline IT SECURITY & 1 & $2.70 \%$ \\
\hline CCNP & 1 & $2.70 \%$ \\
\hline MCSA & 1 & $2.70 \%$ \\
\hline \multicolumn{1}{|c|}{ Total } & & \\
\hline
\end{tabular}

Table 5 shows that MCSE is required in $21.6 \%$ of the adverts followed by A+ (13.51\%). Since Microsoft products are dominant in most organizations, the need for MCSE certification is understandable. However, the number of adverts requiring certifications are few compared to the total number of adverts for early career positions. An interesting finding is that the demand for skill in SAP is growing. This has also been observed in those adverts which required more than 2 years of experience.
The issue related to the demand for industry certifications is a new trend. Even though the demand for certifications for entry-level positions is low in this study, compared to the total number of adverts, it might grow in the future. From our experience, most companies in the country expect their new employees to be able to handle their tasks immediately after employment without much training investment on the incumbents. This is particularly true for small to medium-sized companies where training investment on new employees is not a priority. Such companies usually require certifications and product specific skills from their new employees. Most private companies fall in to this category of companies. Therefore, the demand for certifications for entry-level positions has a challenging implication for academic programmes as certifications and product specific skills are not the primary focus of University education. Nonetheless, it is important to find a balance to minimize the expectation gap between employers' demands and the knowledge and skills provided by academic programmes.

\section{CONCLUSION}

This study attempted to understand the types of computing knowledge and skills in demand in Botswana by analyzing job adverts from the 7 major newspapers in the country for the period January 2008 to December 2008. In particular, the study focused on the identification of the types of computing degrees, job titles, and skills in demand for entry-level positions. For this purpose, 131 (from the total 494 collected) job ads were extracted directly from the newspapers and analyzed.

The findings indicate that the demand for Computer Science degree is still high compared to the other computing degrees. It was also observed that a significant number of adverts specify a number of alternative degrees suggesting that the tasks for which the positions are advertised could be generic. In terms of job titles in demand, Systems Analyst is the highest ranking which is similar to the findings of other studies carried out elsewhere. The findings regarding those skills in demand show that generic skills have the highest ranking in all skills categories. From all the skills categories, web development skills are the least mentioned in the adverts which is in contrary to our expectation where web development is becoming common in other countries. It is also observed that some certifications are frequently required.

We believe that such studies should be conducted regularly by collecting data continuously so that skill demand patterns can be understood properly. This understanding can lead to informed curricula design that can prepare graduates equipped with the necessary skills for employment.

Even though the findings of this study are based only on one year advert data, the result can still be used as a baseline for further studies on the issue. We believe that, in the future, a comprehensive data covering a longer period of time (e.g., 5 10 years data) needs to be collected and analyzed in order to see the trend in the demand for the different computing skills. Once such studies are carried out, students can use the findings to select courses that focus on those skills which are in demand. 
Academic institutions can use the findings so that that those skills in demand can be taken into account during curriculum design.

\section{REFERENCES}

[1] J. Liu, "Computing as an Evolving Discipline: 10 Observations," IEEE Computer, vol. 40, pp. 110 - 112, 2007.

[2] K. L. Chin, "Issues and Challenges in Teaching SE, IT, IS and EC," in 19th Australian Conference on Software Engineering, 2008, pp. 604 610.

[3] M. Gallivan, D. P. T. III, and L. Kvasny, "An Analysis of the Changing Demand Patterns for Information Technology Professionals," in SIGCPR, Kristiansand, Norway, 2002, pp. 1-13.

[4] M. J. Gallivan, D. P. T. III, and L. Kvasny, "Changing Patterns in IT Skill Sets 1988-2003: A Content Analysis of Classified Advertising," ACM SIGMIS Database, vol. 35, pp. 64-87, 2004.

[5] M. A. Kennan, D. Cecez-Kecmanovic, P. Willard, and C. S. Wilson, "IS Knowledge and Skills Sought by Employers: A Content Analysis of Australian Early Career Job Advertisements," Australian Journal of Information Systems, vol. 15, pp. 169-190, 2009.

[6] U. B. o. L. a. Statistics, "Occupational Outlook Handbook," 2010 -11 ed. vol. 2010, U. S. D. o. L. Bureau of Labor Statistics, Ed., 2010.

[7] Y. Choi and E. Rasmussen, "What Qualifications and Skills are Important for Digital Librarian Positions in Academic Libraries: A Job Advertisement Analysis," The Journal of Academic Librarianship, vol. 35, pp. 457-467, 2009.

[8] C. Litecky, A. Aken, A. Ahmed, and H. J. Nelson, "Mining for Computing Jobs," IEEE Software, vol. 27, pp. 78-85, 2010.

[9] S. Surakka, "Trend Analysis of Job Advertisements: What technical skills do software developers need?," Helsinki University of technology 2005.

\section{AUTHORS PROFILE}

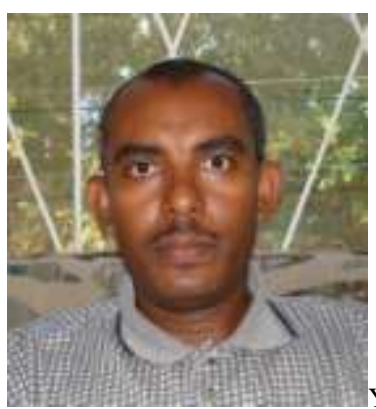

Yirsaw Ayalew is a Senior Lecturer at the Department of Computer Science, University of Botswana. He holds a PhD in computer science from the University of Klagenfurt, Austria and teaches both undergraduate and graduate courses in software engineering and database systems. His research interests are mainly in the area of software engineering; particularly software quality, requirements engineering, software engineering for healthcare systems and end-user software engineering.

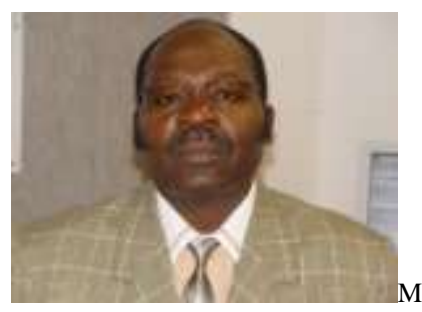
of Computer Science, University of Botswana, Botswana. He currently holds a Bachelor of Science degree, Kenyatta University, Kenya, Master of Science
[10] L. C. Liu, K. S. Koong, and L. Rydl, "A Study of Information Technology Job Skills," in 37th Annual Southwest Region Decision Sciences Institute (SWDSI) Conference, Oklahoma City, 2006, pp. 419426.

[11] P. A. Todd, J. D. McKeen, and R. Brent, "The Evolution of IS Job Skills: a Content Analysis of IS Job Advertisement from 1970 to 1990," MIS Quarterly, vol. 19, pp. 1-27, 1995.

[12] K. Krippendorff, Content Analysis: An Introduction to its Methodology, 2nd ed.: Sage Publications, Inc., 2004.

[13] K. Krippendorf, Content Analysis: An Introduction to Its Methodology: SAGE Publications, 1980.

[14] E. Ettinger, C. Wilderom, and H. Ruel, "Service-Quality Criteria of Web Recruiters: A Content Analysis," in 42nd Hawaii International Conference on Systems Sciences, 2009, pp. 1-10.

[15] CC2005, "Computing Curricula 2005," A Volume of the Computing Curricula Series, pp. 1-62, 2005.

[16] J. F. Nunamaker, J. D. Couger, and G. B. Davis, "Information Systems Curriculum Recommendations for the4 1980s: Undergraduate and Graduate Programs - A Report of the ACM Curriculum Committee on Information Systems," Communications of the ACM, vol. 25, pp. 781805, 1982.

[17] ACS, "Australian Computer Society Job Descriptions." vol. 2010, 2010.

[18] BLS, "Occupational Outlook Handbook," 2010 -11 ed. vol. 2010, U. S. D. o. L. Bureau of Labor Statistics, Ed., 2010.

[19] C. K. Lee and H. J. Han, "Analysis of Skills Requirement for EntryLevel Programmer/Analysts in Fortune 500 Corporations," Journal of Information Systems Education, vol. 19, pp. 17 - 27, 2008.

[20] J. Gorgone and V. Kanabar, "Masters in Information Systems: A WebCentric Model Curriculum," in Informing Science + IT Education, 2002, pp. $553-563$.

degree (information systems) from University of Nairobi, Kenya. He is registered for a $\mathrm{PhD}$ in Computer Science at the University of Western Cape, Cape Town, South Africa. He is professionally qualified CCNA, CCAI, and CCNP in networks. He is also a fellow of Computer Society of Botswana. His research interests include: Mobile Ad Hoc networks, Wireless Sensor Networks, Routing in Networks, Social Networks, Neural Networks and Artificial intelligence, E-learning in networks.

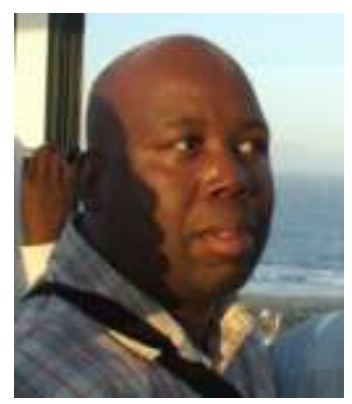

Mr Tallman Z. Nkgau is a lecturer in the Department of Computer Science at the University of Botswana. He holds an H.BSc(Computer Science) from Lakehead University and an MSc(Computer Science) from McGill University. $\mathrm{He}$ is also a certified Cisco Academy Instructor and is CCNP certified. His research interests are in network security, algorithms and data structures, combinatorial optimization and effective use of ICT for development 


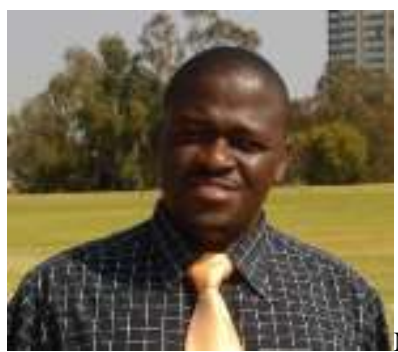

Nkwebi P. Motlogelwa works as a Lecturer in the Department of Computer Science, University of Botswana. His research interests are in high performance computing for socio-economic development. This research aims to utilize prevalent low-cost clusters for socio-economic development. In addition, Motlogelwa has been involved for the past two years in a Microsoft funded project investigating how wireless and mobile technologies can enable under-served communities to benefit from opportunities afforded by the power of information and communication technologies to achieve development goals. His main focus in on how mobile phones can be used in healthcare information dissemination, particularly HIV/AIDS information dissemination to illiterate and semi-illiterate people in rural areas in Botswana.

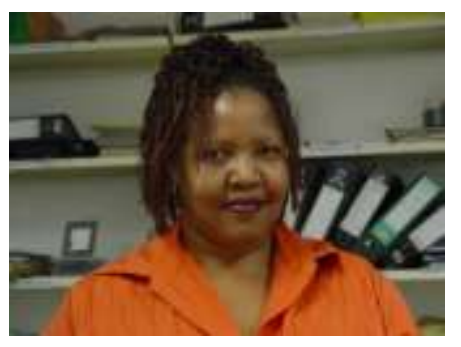

Dr Audrey Masizana-Katongo is a lecturer at University of Botswana, Computer Science Department. She holds a $\mathrm{PhD}$ in computer science from the UMIST in the UK, and teaches both undergraduate and graduate courses in areas with applications of Decision Support Systems and Expert Systems and Web Engineering. Her research interests are mainly in the area of Decision and Intelligent systems; particularly application of mathematical and computing techniques in decision problems. 